\title{
Minimally invasive coronary artery bypass: Twenty-year experience
}

\author{
Alberto Repossini, MD, ${ }^{\mathrm{a}}$ Lorenzo Di Bacco, MD, ${ }^{\mathrm{a}}$ Flavia Nicoli, MD, ${ }^{\mathrm{a}}$ Bruno Passaretti, MD, \\ Alessandra Stara, MD, ${ }^{a}$ Bejko Jonida, $\mathrm{MD},{ }^{a}$ and Claudio Muneretto, $\mathrm{MD}^{\mathrm{a}}$
}

\section{ABSTRACT}

Objective: Minimally invasive direct coronary artery bypass for the left thoracic artery on the left anterior descending artery is a safe and less traumatic surgical technique. We retrospectively evaluated long-term outcomes in a large series of patients undergoing minimally invasive direct coronary artery bypass.

Methods: From 1997 to 2016, 1060 patients underwent minimally invasive direct coronary artery bypass: 646 patients $(61 \%)$ with isolated proximal left anterior descending disease and 414 patients $(39 \%)$ with multivessel disease as a part of hybrid coronary revascularization or in association with medical therapy. Long-term follow-up, major cardiac and cerebral adverse events, and freedom from angina were analyzed.

Results: Mean age of patients was $71 \pm 12.5$ years, and median European System for Cardiac Operative Risk Evaluation II was 3.2\% (interquartile range, $0.6 \%$ $7.8 \%$ ). Postoperative death occurred in 9 patients $(0.8 \%)$, and perioperative stroke occurred in 3 patients $(0.3 \%)$. An angiogram or computed tomography scan was performed and was available in patients within 10 years of follow-up $(n=696)$, demonstrating a $96.8 \%$ graft patency rate. At $13.9 \pm 5.6$ years of follow-up, no surgical reintervention was performed for left thoracic artery on left anterior descending artery graft failure, but 14 patients underwent left anterior descending or left thoracic artery on left anterior descending artery percutaneous coronary intervention. Kaplan-Meier survival curve shows $87.1 \%$ at 5 years (95\% confidence interval, 81-92.5), 84.3\% at 10 years (95\% confidence interval, $77.1-91.4)$, and $79.8 \%$ at 15 years (95\% confidence interval, 72.2-87.3). Survival freedom from major adverse events was $87.0 \%$ (95\% confidence interval, 85.9$88.1)$ at 5 years and $70.5 \%$ (95\% confidence interval, 66.4-74.6) at 15 years.

Conclusions: Minimally invasive direct coronary artery bypass can be safely performed with low postoperative mortality and morbidity with excellent short- and long-term survival and freedom from major adverse events and angina with a reduced surgical invasiveness. (J Thorac Cardiovasc Surg 2019;158:127-38)

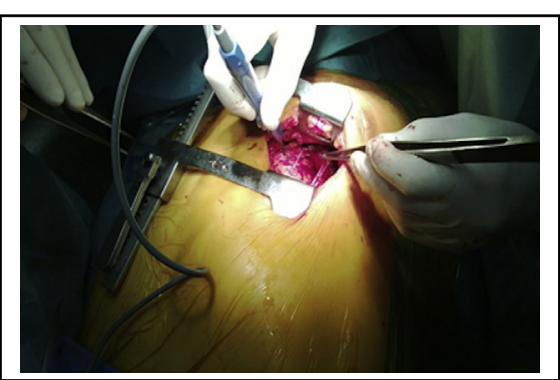

The MIDCAB operation.

Central Message

MIDCAB provides excellent patency results at a long-term follow-up with a low rate of graft failures, avoiding major surgery trauma.

\section{Perspective}

Minimally invasive bypass may be adopted as the technique of choice for patients with single-vessel disease or functional singlevessel disease, or as a part of hybrid strategy. Reduced repeated target vessel revascularization and protection from disease progression, when compared with percutaneous techniques, may improve long-term survival.

See Commentary on page 139 .

\footnotetext{
From the ${ }^{\mathrm{a}}$ Department of Cardiac Surgery, University of Brescia, Brescia, Italy; and ${ }^{\mathrm{b}}$ Department of Cardiology, Clinica Humanitas Gavazzeni, Bergamo, Italy. Read at the 98th Annual Meeting of The American Association for Thoracic Surgery, San Diego, California, April 28-May 1, 2018.

Received for publication April 26, 2018; revisions received Oct 3, 2018; accepted for publication Nov 5, 2018; available ahead of print Feb 7, 2019.

Address for reprints: Alberto Repossini, MD, Cardiac Surgery Unit University of Brescia, Spedali Civili, Piazza Spedali Civili 1, 25123, Brescia, Italy (E-mail: arepossini@yahoo.it).

$0022-5223 / \$ 36.00$

Copyright (c) 2019 by The American Association for Thoracic Surgery

https://doi.org/10.1016/j.jtcvs.2018.11.149
}

Well-established therapeutic options for patients with severe proximal stenosis of the left anterior descending (LAD) coronary artery are conventional sternotomy

Uf Scanning this QR code will
take you to the article title
page to access supplementary
information. To view the
AATS Annual Meeting Web-
cast, see the URL next to the
webcast thumbnail.




\section{Abbreviations and Acronyms \\ $\mathrm{CABG}=$ coronary artery bypass grafting \\ $\mathrm{CI}=$ confidence interval \\ $\mathrm{CPB}=$ cardiopulmonary bypass \\ CT = computed tomography \\ DES = drug-eluting stent \\ LAD $=$ left anterior descending \\ LITA $=$ left internal thoracic artery \\ MACCE $=$ major adverse cardiac and cerebrovascular events \\ $\mathrm{MIDCAB}=$ minimally invasive direct coronary artery bypass \\ OMT = optimal medical therapy \\ PCI = percutaneous coronary intervention}

bypass grafting, minimally invasive direct coronary artery bypass (MIDCAB), and percutaneous coronary intervention (PCI) with bare-metal stents or drugeluting stents (DES). ${ }^{1-3}$

According to the most recent guidelines ${ }^{4}$ advocating a surgical or interventional revascularization in case of proximal LAD lesions, PCI is still considered the patient's preferred choice, mainly for its reduced invasiveness.

MIDCAB has gained wide acceptance, because it eliminates sternal incision, aortic manipulation, and cardiopulmonary bypass $(\mathrm{CPB})$, achieving the same patency rates of conventional surgery, ${ }^{5}$ but in many centers it is seldom considered the method of choice for LAD surgical revascularization in isolated LAD lesions. MIDCAB has been used in our institution as the technique of choice since 1997 in patients with isolated proximal LAD lesions or in highrisk patients with multivessel disease as part of a hybrid revascularization strategy. We present the results of our 20-year experience in MIDCAB to evaluate the long-term outcomes.

\section{PATIENTS AND METHODS}

From May 1997 to June 2016, 1060 patients underwent standard MIDCAB through a small anterolateral left minithoracotomy in our Cardiac Surgery Centers. This is a retrospective study on data prospectively collected, with the aim to analyze the long-term result, of our series.

Patients have been assessed in 2 different clinical/therapeutic groups:

- MIDCAB group (646 patients): These patients had isolated LAD disease, and a PCI was not recommended (type $\mathrm{C}$ lesions according to Fitzgibbon's) ${ }^{6}$ or not possible (LAD occluded); functional single-vessel disease, defined as LAD disease when a coexisting multivessel disease, will not be treated anyway for small-vessel diameter, diffuse disease, irreversible ischemic damage, or distal vessel hypoplasia. In this group, no particular patient selection criteria were applied, all patients with isolated LAD disease unsuitable for PCI were considered for MIDCAB (excluding the very diseased poor LAD target only), and no patient received a left internal thoracic artery (LITA)-LAD graft through median sternotomy in the analyzed period.
- Multivessel disease group (414 patients): These patients had multivessel disease with functional incomplete revascularization and optimal medical treatment or hybrid coronary revascularization. These patients had severe comorbidities contraindicating sternotomy or CPB (ie, cancer, severe renal failure, cerebrovascular disease, chronic obstructive pulmonary disease, chest irradiation, and morbid obesity), and MIDCAB was performed as a palliative procedure (MIDCAB + optimal medical therapy [OMT]); in this group, 197 patients (18.6\%) had LAD disease and a second-vessel disease that could be treated with PCI before or after surgical treatment and evaluation of residual ischemia (hybrid group, hybrid coronary revascularization).

All patients, particularly with regard to possible incomplete revascularization and hybrid strategy, gave complete informed consent. Ethical Committee authorization was achieved for retrospective analysis of data. Preoperative data are shown in Table 1.

Preoperative antiplatelet treatment was suspended according to guidelines indications, ${ }^{7}$ but patients with bare-metal stents or DES were administered double-antiplatelet therapy for operation. Urgent revascularization was achieved in 46 patients $(4.3 \%)$, and emergency revascularization was achieved in 7 patients $(0.6 \%)$.

\section{Surgical Technique}

The operation was performed through a $5-\mathrm{cm}$ anterolateral minithoracotomy and LITA harvested under direct vision with the ThoraTrak MICS Retractor (Medtronic Inc, Minneapolis, Minn) (Video 1). Double-lumen selective tracheal intubation, although potentially useful, was never necessary, being the anterior part of the left lung retracted with a tissue pad.

The technique of choice for LITA takedown is skeletonization with hemoclips. The Harmonic scalpel (Ethicon Endosurgery, Cincinnati, Ohio), not available at our institute at the beginning of our experience, was never used for LITA takedown. Our standard approach is from the fourth intercostal space, and the LITA is dissected as proximally as possible reaching the first intercostal space to achieve maximum length and mobilization. After opening the pericardium and LAD identification, before LITA distal transection, we check the effective LITA length considering how lateral and distal the anastomotic site should be, and the invasiveness in the lung, and, when the case ( $\sim 5 \%$ of cases), we open the fifth intercostal space from the same skin incision and complete LITA harvesting distally for 3 to $4 \mathrm{~cm}$ more. This allowed us to resolve nearly all LITA length problems, and conversions to full sternotomy are limited to deep intramural or massively calcified LAD.

In patients with severe chronic obstructive pulmonary disease and emphysema, MIDCAB may be hazardous for possible excessive traction on the graft of hyperinflated lungs, and the only way to minimize this risk is LITA harvesting as proximally as possible to allow maximal length; otherwise, a conversion via sternotomy is recommended.

Heparin was administered at the dose of $1 \mathrm{mg} / \mathrm{kg}$, and activated clotting time was kept at greater than 300 seconds during the operation. A reusable pressure stabilizer without suction was used in the first 15 years, and a disposable transthoracic suction stabilizer (Nuvo, Medtronic Inc) was used in the following years. Proximal occlusion was performed with a 4-0 pledgeted suture. No coronary shunts were used, but we routinely apply a preconditioning of 8-minute LAD occlusion followed by 1 minute of reperfusion before the anastomosis. Further details of the operative technique are reported by Repossini and colleagues. ${ }^{8}$

\section{Postoperative Management}

LITA angiographic control was performed in the first 150 patients on postoperative day 3. No intraoperative flow probes were available in our institution at the time of the study.

Acetylsalicylic acid $100 \mathrm{mg}$ as an antiplatelet drug was started on operative day 1 and recommended indefinitely. Dual antiplatelet therapy with 
TABLE 1. Preoperative comorbidities and characteristics of patients

\begin{tabular}{|c|c|c|c|c|}
\hline Patient characteristics & $\begin{array}{c}\text { MIDCAB } \\
n=1060 \\
n(\%)\end{array}$ & $\frac{\frac{\text { MIDCAB (SVD) }}{n=646}}{n(\%)}$ & $\begin{array}{c}\text { HCR } \\
\mathbf{n}=197 \\
\mathbf{n}(\%)\end{array}$ & $\frac{\frac{\text { MIDCAB + OMT }}{n=217}}{n(\%)}$ \\
\hline Female gender & $158(14.9)$ & $65(10.1)$ & $37(18.8)$ & $54(24.8)$ \\
\hline Age $(y)($ mean \pm SD) & $71 \pm 12$ & $71.9 \pm 9.1$ & $77.8 \pm 7.5$ & $75.7 \pm 6.9$ \\
\hline Active smokers & $341(32.2)$ & $174(26.9)$ & $72(36.5)$ & 95 (43.7) \\
\hline $\mathrm{BMI}>30$ & $40(3.8)$ & $15(3.7)$ & $3(2.5)$ & $2(1.5)$ \\
\hline Hypertension & $624(58.9)$ & $194(48.0)$ & $61(50.8)$ & $70(51.5)$ \\
\hline Ejection fraction (mean $\pm \mathrm{SD})$ & $52.6 \pm 15.2$ & $57.7 \pm 16.3$ & $52.8 \pm 17.7$ & $54.6 \pm 12.8$ \\
\hline $\mathrm{EF}<45 \%$ & $60(5.7)$ & $27(4.5)$ & $14(7.1)$ & $19(8.7)$ \\
\hline \multicolumn{5}{|l|}{ Diabetes } \\
\hline ID & $50(4.7)$ & $7(1.7)$ & $9(7.5)$ & $3(2.2)$ \\
\hline NIDD & $227(21.4)$ & $56(13.8)$ & $35(29.1)$ & $21(15.4)$ \\
\hline Dyslipidemia & $537(50.7)$ & $170(42.1)$ & $54(45.0)$ & $63(46.3)$ \\
\hline COPD & $93(8.8)$ & $14(3.5)$ & $19(15.8)$ & $11(8.1)$ \\
\hline PAD & $127(12.0)$ & $21(5.2)$ & $29(24.1)$ & $11(8.1)$ \\
\hline Atrial fibrillation & $47(4.4)$ & $11(1.7)$ & $15(7.6)$ & $21(9.6)$ \\
\hline Previous CVA & $50(4.7)$ & $9(2.2)$ & $10(8.3)$ & $6(4.4)$ \\
\hline Chronic renal failure & $24(2.2)$ & $19(4.7)$ & $11(9.1)$ & $8(5.9)$ \\
\hline Critical preoperative state & $59(5.5)$ & $12(3.0)$ & $10(8.3)$ & $8(5.8)$ \\
\hline Unstable angina & $90(8.5)$ & $47(7.2)$ & $26(13.1)$ & $17(7.8)$ \\
\hline STEMI/nSTEMI $<90 \mathrm{gg}$ & $62(5.8)$ & $20(4.9)$ & $25(20.8)$ & $47(34.5)$ \\
\hline Pulmonary hypertension & $21(1.9)$ & $6(1.5)$ & $2(1.6)$ & $3(2.2)$ \\
\hline Redo & $51(4.8)$ & $16(4.0)$ & $20(16.6)$ & $14(10.3)$ \\
\hline Previous PCI & $46(4.3)$ & $14(3.5)$ & $9(7.5)$ & $32(23.5)$ \\
\hline euroSCORE (median) & $3.2 \%$ & $1.7 \%$ & $2.7 \%$ & $4.4 \%$ \\
\hline 25th-75th quartiles & $0.6 \%-7.8 \%$ & $0.6 \%-2.7 \%$ & $0.7 \%-4.1 \%$ & $1.3 \%-6.8 \%$ \\
\hline
\end{tabular}

$M I D C A B$, Minimally invasive direct coronary artery bypass; $S V D$, single-vessel disease; $H C R$, hybrid coronary revascularization; $O M T$, optimal medical therapy; SD, standard deviation; $B M I$, body mass index; $E F$, ejection fraction; $I D$, insulin dependent; $N I D D$, noninsulin dependent; $C O P D$, chronic obstructive pulmonary disease; $P A D$, peripheral artery disease; CVA, cerebrovascular accident; STEMI, ST-elevation myocardial Infarction; PCI, percutaneous coronary intervention; euroSCORE, European System for Cardiac Operative Risk Evaluation.

clopidogrel or ticagrelor was administered from postoperative day 2 after drainage removal for 6 months after surgery to ameliorate the graft patency rate. ${ }^{9}$

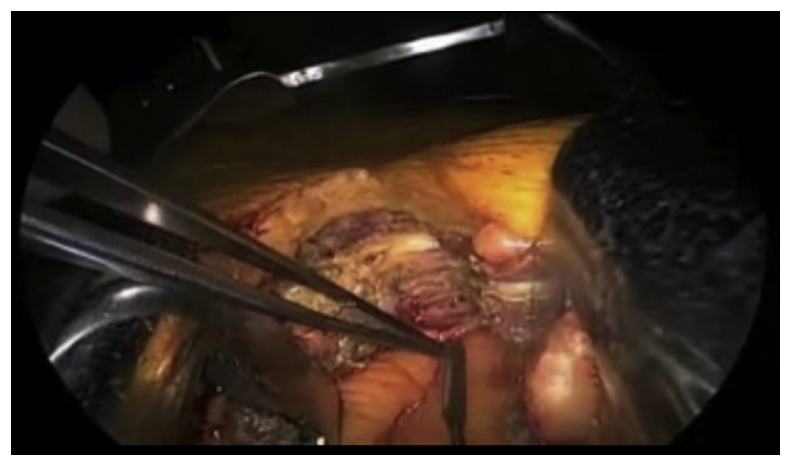

VIDEO 1. The MIDCAB live surgical case. Video available at: https:// www.jtcvs.org/article/S0022-5223(18)33517-7/fulltext.

\section{Data Collection and Follow-up Methods}

Preoperative, intraoperative, and postoperative data, as well as angiographic findings, were collected from written and electronic files. For asymptomatic patients, no further routine invasive studies were performed, and a cyclo-ergometer stress test was recommended every 12 months with a cardiologic follow-up. In case of symptom recurrence and electrocardiographic or scintigraphy findings of ischemia, angiography was performed, and the decision about further revascularization procedures or optimal medical treatment (OMT) was left to the referring cardiologist. In asymptomatic patients with subcritical non-LAD lesions or for different clinical reasons, a coronary computed tomography (CT) scan was performed during follow-up to check progression of the coronary artery disease.

Data were collected on survival, general conditions, freedom from angina, number of hospitalizations, freedom from major cardiac, and cerebral adverse events, including myocardial infarction, stroke, cardiac death, and target vessel revascularization. Periprocedural acute myocardial infarction was defined as electrocardiographic modifications with ratio of creatine kinase-MB to total creatine kinase exceeding 0.1. Troponin evaluation was not routinely used because the high-sensibility troponin routine is clinical practice for acute coronary syndromes since it was introduced in 
TABLE 2. Postoperative complications

\begin{tabular}{|c|c|c|c|c|}
\hline Postoperative complications & $\frac{\frac{\text { MIDCAB }}{n=1060}}{n(\%)}$ & $\frac{\frac{\text { MIDCAB (SVD) }}{n=646}}{n(\%)}$ & $\begin{array}{c}\text { HCR } \\
n=197 \\
n(\%)\end{array}$ & $\frac{\frac{\text { MIDCAB }+ \text { OMT }}{n=217}}{\mathbf{n}(\%)}$ \\
\hline $\operatorname{LOS}(\mathrm{d})($ mean $\pm \mathrm{SD})$ & $5.4 \pm 1.1$ & $5.1 \pm 6.8$ & $5.9 \pm 9.1$ & $6.4 \pm 8.7$ \\
\hline ICU stay $(\mathrm{h})($ mean $\pm \mathrm{SD})$ & $21.8 \pm 8$ & $18.7 \pm 7.8$ & $22.5 \pm 9.1$ & $23.1 \pm 9.5$ \\
\hline Early death & $9(0.8)$ & $3(0.4)$ & $2(1.0)$ & $4(1.8)$ \\
\hline Stroke & $3(0.3)$ & $1(0.2)$ & $0(0.0)$ & $2(0.9)$ \\
\hline \multicolumn{5}{|l|}{ Rethoracotomy for bleeding } \\
\hline Sternotomy & $0(0)$ & $0(0.0)$ & $0(0.0)$ & $0(0.0)$ \\
\hline Lateral minithoracotomy & $19(1.8)$ & $10(1.5)$ & $5(2.5)$ & $4(1.8)$ \\
\hline Bleeding $>1000 \mathrm{~mL}$ without reoperation & $21(2.0)$ & $8(1.2)$ & $9(4.5)$ & $4(1.8)$ \\
\hline \multicolumn{5}{|l|}{ Low cardiac output } \\
\hline Prolonged catecholamines & $6(0.6)$ & $2(0.3)$ & $1(0.5)$ & $3(1.4)$ \\
\hline $\mathrm{IABP}$ & $13(1.2)$ & $4(0.6)$ & $2(1.0)$ & $7(3.2)$ \\
\hline Myocardial infarction & $16(1.5)$ & $5(0.7)$ & $4(2.0)$ & $7(3.2)$ \\
\hline Temporary significant CK increase & $13(1.2)$ & $4(0.6)$ & $3(1.5)$ & $6(2.7)$ \\
\hline Temporary significant ST-elevation & $7(0.7)$ & $3(0.4)$ & $1(0.5)$ & $2(0.9)$ \\
\hline New atrial fibrillation onset & $93(8.8)$ & $49(7.5)$ & $19(9.6)$ & $25(11.5)$ \\
\hline Ventricular fibrillation & 0 & $0(0.0)$ & $0(0.0)$ & $0(0.0)$ \\
\hline Atelectasis of lower left lobe & $133(12.5)$ & 77 (11.9) & $27(13.7)$ & $29(13.3)$ \\
\hline Pneumothorax & $21(2.0)$ & $9(1.4)$ & $5(2.5)$ & $7(3.2)$ \\
\hline Pleural effusion & $102(9.6)$ & $51(7.8)$ & $20(10.1)$ & $31(14.2)$ \\
\hline Acute renal dysfunction & $10(0.9)$ & $4(0.6)$ & $2(1.0)$ & $5(2.3)$ \\
\hline Early reoperation (sternotomy) & $3(0.3)$ & $1(0.2)$ & $0(0.0)$ & $2(0.9)$ \\
\hline
\end{tabular}

$\overline{M I D C A B}$, Minimally invasive direct coronary artery bypass; $S V D$, single-vessel disease; $H C R$, hybrid coronary revascularization; $O M T$, optimal medical therapy; $L O S$, length of stay; $S D$, standard deviation; $I C U$, intensive care unit; $I A B P$, intra-aortic balloon pump; $C K$, creatinine kinase.

2007. Standard definitions of myocardial infarction criteria were applied at follow-up. ${ }^{10}$ Any new revascularization on LAD by PCI or bypass grafting was considered as target vessel revascularization. Stent thrombosis was defined with standard criteria. ${ }^{11}$
Long-term follow-up analysis was performed on the overall population to evaluate overall survival, cardiac-related mortality, and major adverse cardiac and cerebrovascular events (MACCE) (all-cause death, acute myocardial infarction, LITA-LAD PCI, stroke), and LITA-LAD

TABLE 3. Event rate at follow-up

\begin{tabular}{|c|c|c|c|c|c|c|}
\hline Variable & $\begin{array}{l}\text { Early events } \\
(\leq \mathbf{3 0} \text { d) n }(\%)\end{array}$ & $\begin{array}{c}\text { Follow-up } \\
\text { (median) } \\
\text { IQR }\end{array}$ & $\begin{array}{l}\text { Late events }(>\mathbf{3 0} \mathbf{d}) \mathbf{n} \\
\quad(\text { linearized rate })\end{array}$ & $\begin{array}{l}95 \% \text { CI linearized } \\
\text { rate }\end{array}$ & $\begin{array}{l}\text { Survival/freedom } \\
\text { from event at } 5 \mathrm{y}\end{array}$ & $\begin{array}{l}\text { Survival/freedom } \\
\text { from event at } 15 \mathrm{y}\end{array}$ \\
\hline Mortality & $9(0.8 \%)$ & $\begin{array}{l}11.1 \mathrm{y} \\
6.8-14.8\end{array}$ & 208 (1.5\%/ey) & $(1.3 \%-1.5 \%)$ & $87.1 \% \pm 5.1 \%$ & $79.8 \% \pm 6.6 \%$ \\
\hline Cardiac-related mortality & $4(0.4 \%)$ & $\begin{array}{l}11.1 \mathrm{y} \\
6.8-14.8\end{array}$ & $131(1.0 \% /$ ey $)$ & $(0.8 \%-1.2 \%)$ & $92.1 \% \pm 4.6 \%$ & $85.3 \% \pm 6.3 \%$ \\
\hline Acute myocardial infarction & $16(1.5 \%)$ & $\begin{array}{l}11.8 \mathrm{y} \\
7.2-15.0\end{array}$ & 27 (0.34\%/ey) & $(0.2 \%-0.4 \%)$ & $98.6 \% \pm 0.5 \%$ & $96.1 \% \pm 0.8 \%$ \\
\hline $\begin{array}{l}\text { Target vessel } \\
\text { revascularization for LITA }\end{array}$ & - & $\begin{array}{l}12.0 \mathrm{y} \\
6.6-14.4\end{array}$ & $36(0.33 \% /$ ey $)$ & $(0.2 \%-0.5 \%)$ & $98.7 \% \pm 0.7 \%$ & $95.3 \% \pm 0.9 \%$ \\
\hline Stroke & $3(0.3 \%)$ & $\begin{array}{l}11.9 \mathrm{y} \\
7.0-15.0\end{array}$ & $41(0.4 \% /$ ey $)$ & $(0.3 \%-0.6 \%)$ & $98.8 \% \pm 0.4 \%$ & $91.4 \% \pm 0.9 \%$ \\
\hline MACCE & $25(2.4 \%)$ & $\begin{array}{l}10.2 \text { y } \\
5.5-13.6\end{array}$ & 225 (1.7\%/ey) & $(1.4 \%-1.9 \%)$ & $87.8 \% \pm 1.1 \%$ & $70.5 \% \pm 4.1 \%$ \\
\hline
\end{tabular}

IQR, Interquartile range; $C I$, confidence interval; ey, event per year; LITA, left internal thoracic artery; MACCE, major adverse cardiac and cerebrovascular events. 


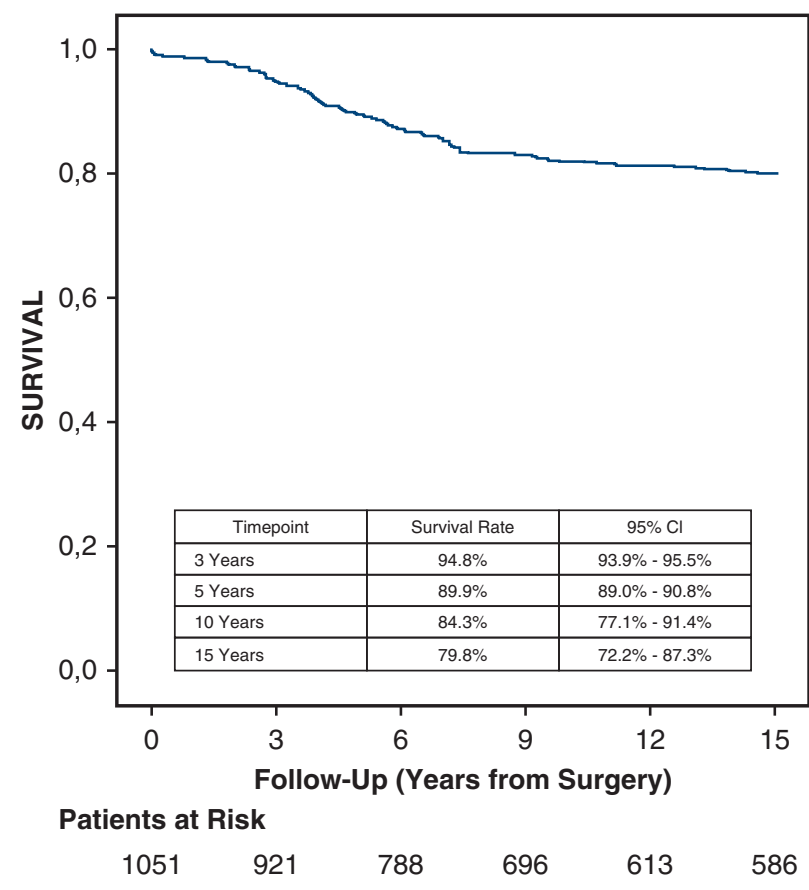

A

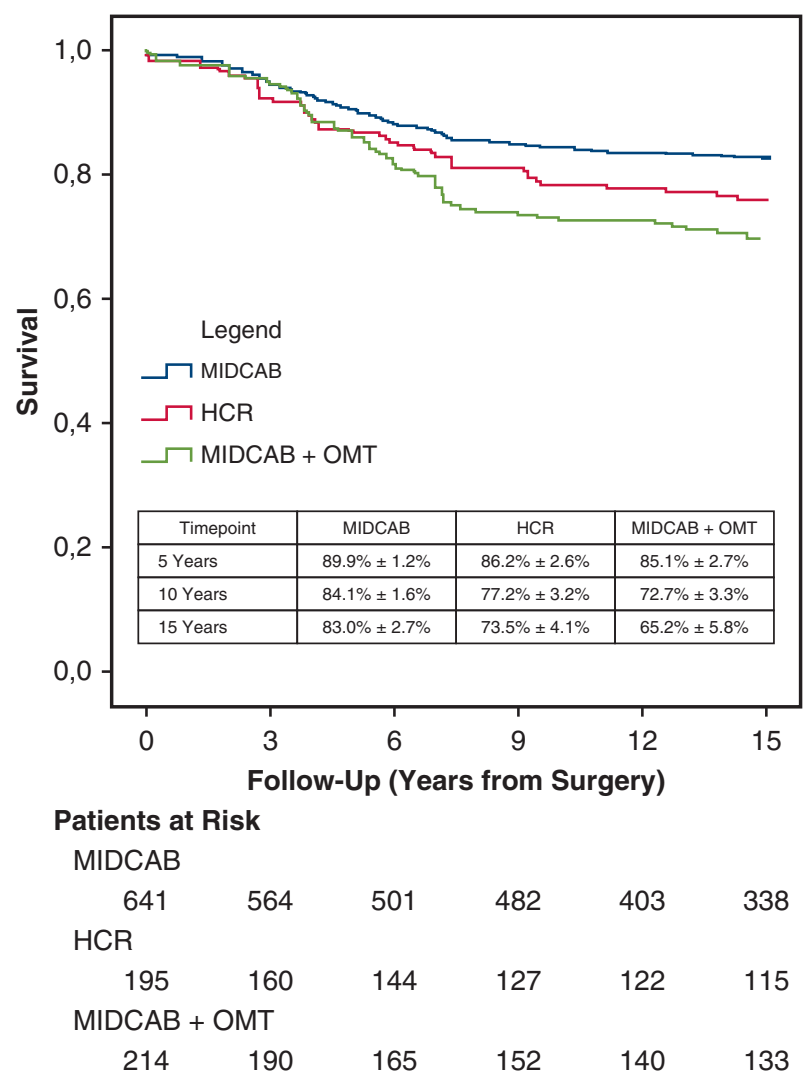

B

FIGURE 1. A, Kaplan-Meier survival freedom from all-cause death. B, Stratified outcomes for survival freedom from all-cause death. MIDCAB performed in patients with single-vessel disease. MIDCAB + OMT performed in patients with multivessel disease. CI, Confidence interval; $M I D C A B$, minimally invasive direct coronary artery bypass; $H C R$, hybrid coronary revascularization; $O M T$, optimal medical therapy.

graft patency. Outcomes are reported on the intention-to-treat approach cohort.

\section{Statistical Analysis}

Statistical analysis was performed with IBM SPSS Statistics for Windows, Version 20.0, released 2011 (IBM Corp, Armonk, NY). Continuous variables are tested for normality, and variables with normal distribution are reported as mean \pm standard deviation. Variables with not normal distribution are reported with median and interquartile range. Discrete variables are reported as number and percentage. Linearized rates of follow-up events incidence are reported according to the indications by Grunkemeier and colleagues. ${ }^{12}$ Freedom from events survival analysis was performed by Kaplan-Meier analysis.

\section{RESULTS}

\section{Intraoperative and Postoperative Course}

The mean procedural time was $91 \pm 12$ minutes. LAD occlusion time was relatively constant with a mean of $13 \mathrm{mi}-$ nutes (range, 8-17 minutes). Urgent revascularization was achieved in 46 patients $(4.3 \%)$, and emergency revascularization was achieved in 7 patients $(0.6 \%)$.

Intraoperative hemodynamics were stable in all patients but $5(0.5 \%)$ who required intravenous infusion of dobutamine for ventricular output decrease and pulmonary artery pressure elevation. Conversion to sternotomy was required in 22 patients $(2.1 \%)$, and in 12 $(1.1 \%)$ of them CPB was necessary to perform a safe anastomosis. No conversion to CBP was necessary for hemodynamic reasons. No ventricular fibrillation occurred. A direct anastomosis of LITA to LAD was obtained in all cases, and no LITA elongation was required. No patient received other graft than end-side LITA-LAD graft. Median logistic European System for Cardiac Operative Risk Evaluation II was 3.2\% (interquartile range, 0.6-7.8).

Nine patients $(0.8 \%)$ died in the perioperative period (30 days): Within the first 48 postoperative hours, 2 of them died of sudden cardiac arrest unresponsive to resuscitation techniques; in 1 case, emergency CPB was started and surgical revision revealed LITA avulsion. A saphenous bypass was performed, and a centrifugal pump was used as the left ventricular assist device; nevertheless, the patient died of irreversible cardiogenic shock. Two patients had a fatal myocardial infarction, 1 due to LITA dissection after MIDCAB. Three patients died suddenly within 30 days. One patient died after respiratory failure and acute 


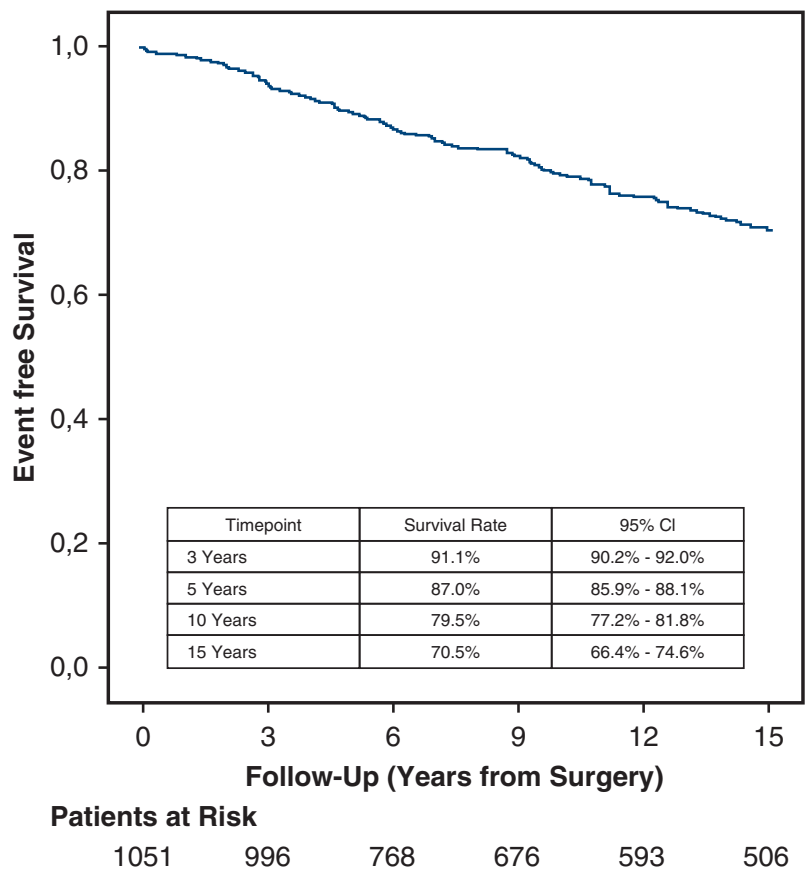

A

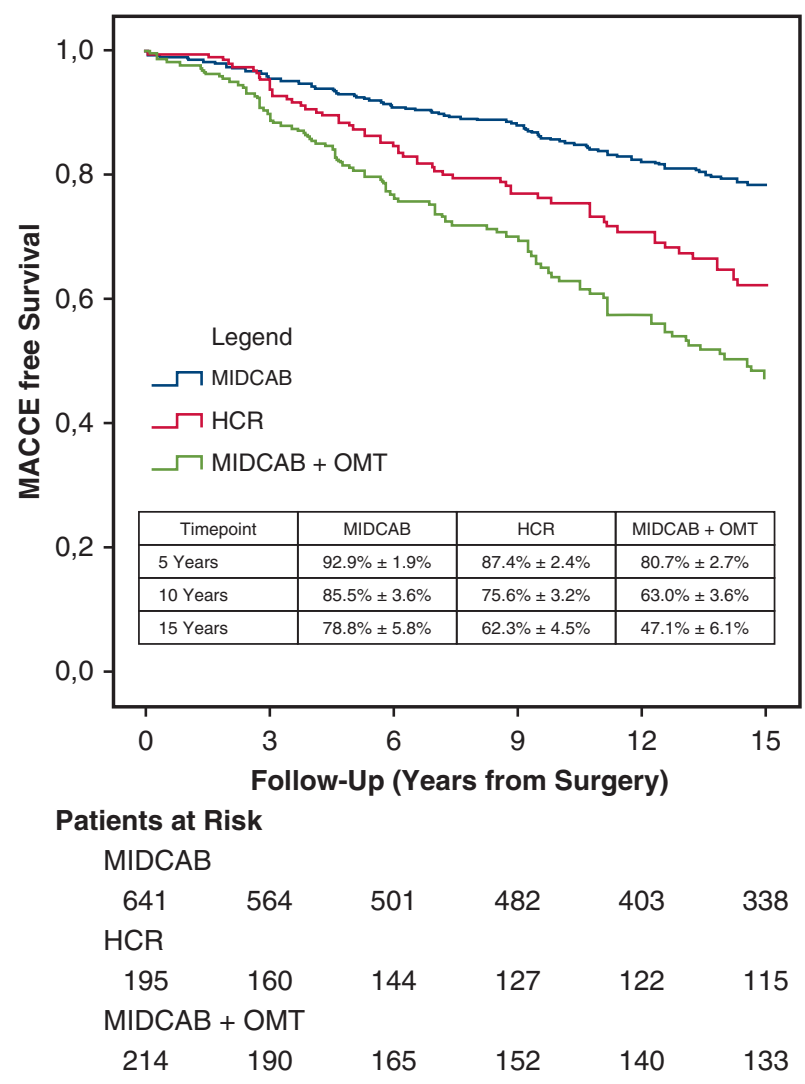

B

FIGURE 2. A, Survival freedom from cardiac death. B, Stratified outcomes for survival freedom from cardiac death. MIDCAB performed in patients with single-vessel disease. MIDCAB + OMT performed in patients with multivessel disease. $C I$, Confidence interval; MACCE, major adverse cardiac and cerebrovascular events; $M I D C A B$, minimally invasive direct coronary artery bypass; $H C R$, hybrid coronary revascularization; $O M T$, optimal medical therapy.

respiratory distress syndrome. One patient with preoperative end-stage renal failure and dialysis had heart failure and sepsis leading to death.

Postoperative acute myocardial infarction occurred in 16 patients $(1.5 \%)$; in 2 of them, nonfatal cases, an intraoperative LAD thromboendarterectomy was performed because of massive calcifications, and postoperative angiography showed reduced LAD runoff. In 1 patient, the procedure was performed as a redo operation, and postoperative angiography revealed distal occlusion of the apical portion of the LAD perhaps due to embolization from the occluded saphenous graft during manipulation in LITA harvesting. The other patients released only creatine kinase-MB without hemodynamic and wall motion alterations. Angiographic controls showed patent LITA-LAD grafts in all these patients.

Three patients had an intramyocardial LAD; in 2 patients, careful dissection of the myocardial tissue was performed under stabilization and the LAD was found; in 1 patient, the LITA was wrongly implanted on a diagonal branch, and after angiographic control, the patient underwent reoperation via sternotomy and $\mathrm{CPB}$.
In 19 patients (1.8\%), surgical revision for bleeding was required, and the problem was resolved through the same thoracotomy incision. In all patients, thoracic artery collateral branches or chest wall thoracic satellite veins were the cause of bleeding.

Average 24-hour postoperative bleeding was $333 \pm 150 \mathrm{~mL}$. Patients were treated with $20 \mathrm{~mL}$ bupivacaine $0.5 \%$ administered every 6 hours through an intrapleural catheter or intravenous $1.25 \mathrm{mg} / \mathrm{kg}$ tramadol every 6 hours on postoperative days 1 and 2 .

No early target vessel reintervention was performed for stenosis of the anastomosis, stenosis of LAD distal to anastomosis, LITA narrowing, or kinking. Urgent stenting of native target vessel was never required. Postoperative details are shown in Table 2.

\section{Follow-up Data}

Median follow-up was 11.1 years (interquartile range, 6.8-14.8 years). Follow-up was $98.8 \%$ complete, and coronary angiography or CT scans were available in all patients within 10 years of follow-up $(n=696)$ with a LITA-LAD patency rate of $96.8 \%$. Time distribution of 


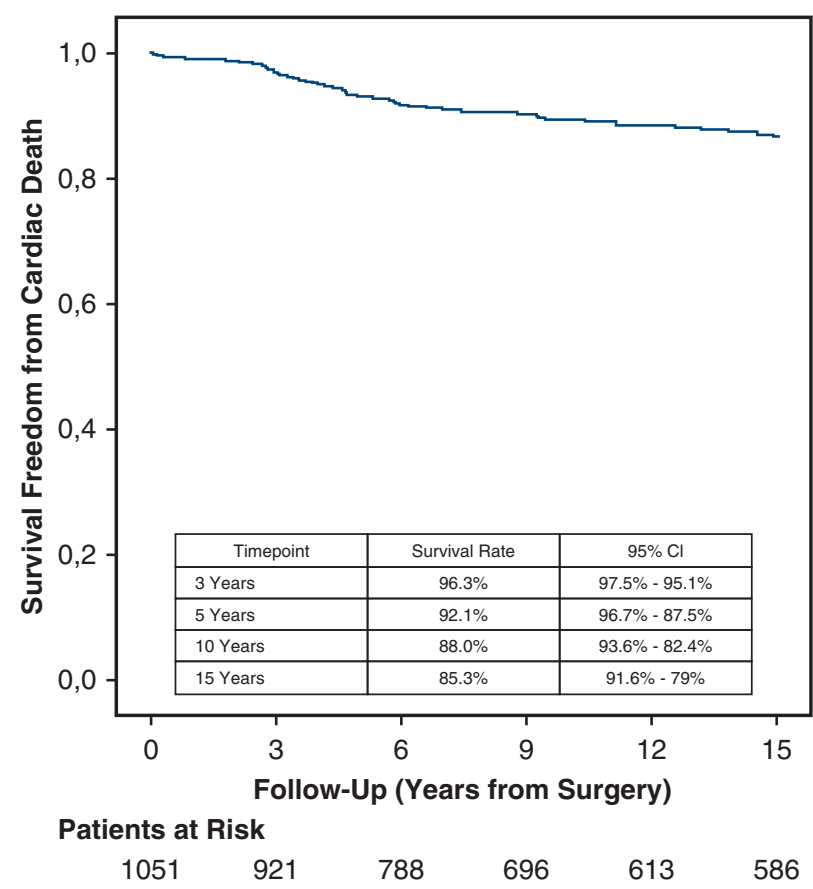

\section{A}

FIGURE 3. A, Survival freedom from MACCE. B, Stratified outcomes for survival freedom from MACCE. MIDCAB performed in patients with singlevessel disease. MIDCAB + OMT performed in patients with multivessel disease. $C I$, Confidence interval; $M I D C A B$, minimally invasive direct coronary artery bypass; $H C R$, hybrid coronary revascularization; $O M T$, optimal medical therapy.

follow-up angiographies and CT scans are shown in Figure E1.

In our series, we report 208 deaths, and $131(1.1 \%$ / events-years) were cardiac related. In patients with cardiac-related deaths, 4 were graft related; other causes were acute myocardial infarctions in other than LAD areas, congestive heart failure, or sudden death. Complete data are listed in Table 3.

At 5, 10, and 15 years of follow-up, actuarial overall survival was $87.1 \%$ (95\% confidence interval [CI], 81-92.5), $84.3 \%$ (95\% CI, 77.1-91.4), and 79.8\% (95\% CI, 72.287.3), respectively (Figure 1, $A$; stratified data are reported in Figure 1, $B$ ). Kaplan-Meier analysis for cardiac-related mortality showed at 5,10 , and 15 years of follow-up an actuarial survival of $92.1 \%$ (95\% CI, 87.5-96.7), 88\% (95\% CI, 82.4-93.6), and 85.3\% (95\% CI, 79-91.6), respectively (Figure 2, $A$; stratified data are reported in Figure 2, $B$ ).

Major adverse cardiac and cerebrovascular events (MACCE) occurred in 225 patients (Table 3); among these, 36 had graft malfunctioning or occlusion treated with PCI or coronary artery bypass surgery in 5 cases. LITA-LAD

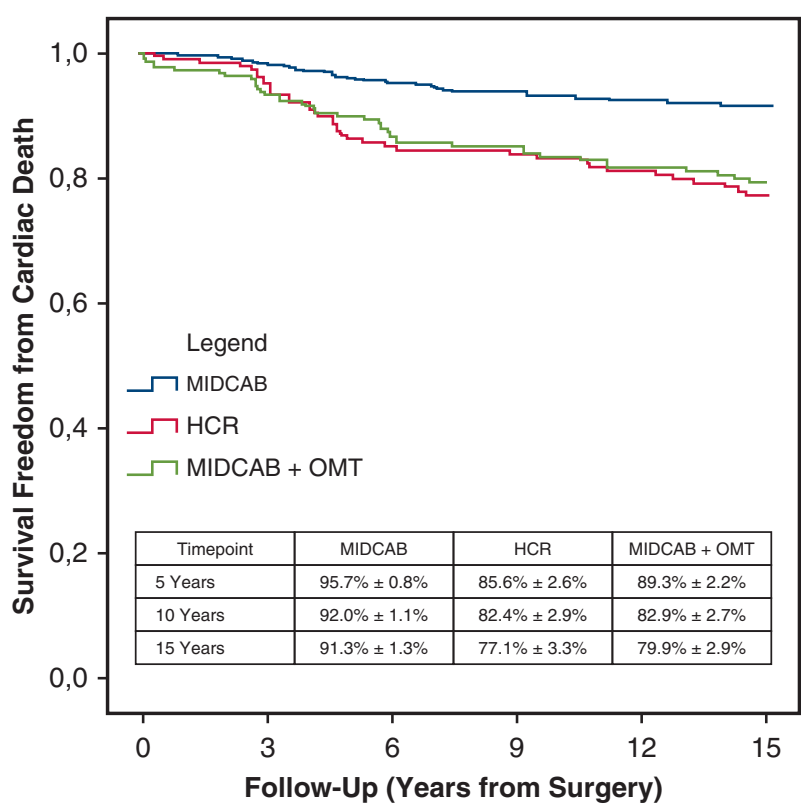

Patients at Risk

$\begin{array}{lccccc}\begin{array}{l}\text { MIDCAB } \\ 641\end{array} & 564 & 501 & 482 & 403 & 338 \\ \text { HCR } & & & & & \\ \begin{array}{l}195 \\ \text { MIDCAB }+ \text { OMT }\end{array} & 160 & 144 & 127 & 122 & 115 \\ 214 & 190 & 165 & 152 & 140 & 133\end{array}$

B

graft causes of dysfunction were occlusion in 21 cases (in 7 cases for possible competitive flow) and LITA-LAD anastomosis stenosis in 15 cases. Survival freedom from target vessel revascularization on the non-LAD vessel in patients who received hybrid coronary revascularization at 15 years was $73.5 \%$ (95\% CI, 69.5-77.5) (Figure E2). Prevalence of angina at 15 years was $7.2 \%$.

Kaplan-Meier analysis for survival freedom from MACCE showed 5-, 10-, and 15-year survival of $87.0 \%$ (95\% CI, 85.9-88.1), 79.5\% (CI, 77.2-81.8), and 70.5\% (95\% CI, 66.4-74.6), respectively (Table 3) (Figure 3, A; stratified data are reported in Figure $3, B$ ). Multivariable analyses for death and MACCE are reported in Table 4.

\section{Comment}

LITA patency on the LAD is the most important determinant for survival and event-free survival after coronary revascularization. ${ }^{13}$ This unique advantage has been historically related to the high invasiveness due to sternotomy and associated $\mathrm{CPB}$, thus popularizing PCI stenting procedures, despite worse long-term results in terms of patency rates and higher repeated procedure rates. ${ }^{14}$ 
TABLE 4. Univariable and multivariable analyses for all-cause death and major adverse cardiac and cerebrovascular events

\begin{tabular}{|c|c|c|c|c|}
\hline \multicolumn{5}{|c|}{ Cox regression for all-cause death } \\
\hline \multirow[b]{2}{*}{ Variables } & \multicolumn{2}{|c|}{ Univariable } & \multicolumn{2}{|c|}{ Multivariable } \\
\hline & HR $(95 \%$ CI $)$ & $P$ value & HR $(95 \%$ CI) & $P$ value \\
\hline Age $>75 y$ & $1.07(0.7-1.3)$ & .891 & $1.05(1.01-1.10)$ & .015 \\
\hline Ejection fraction $<45 \%$ & $1.62(1.08-2.42)$ & .045 & $1.89(1.18-3.02)$ & .013 \\
\hline Female gender & $1.34(0.54-1.86)$ & .823 & & \\
\hline Chronic renal failure & $1.80(1.02-3.30)$ & .042 & $2.51(1.09-4.21)$ & .018 \\
\hline Peripheral artery disease & $1.10(0.55-1.45)$ & .658 & & \\
\hline Diabetes & $2.21(0.87-3.30)$ & .453 & & \\
\hline Chronic obstructive pulmonary disease & $1.34(0.03-1.70)$ & .782 & & \\
\hline Multivessel disease & $1.42(0.99-1.85)$ & .086 & & \\
\hline STEMI/nSTEMI $<90 \mathrm{~d}$ & $1.01(0.78-1.12)$ & .085 & $1.02(1.01-1.04)$ & .006 \\
\hline \multicolumn{5}{|c|}{ Cox regression for MACCE } \\
\hline & \multicolumn{2}{|c|}{ Univariable } & \multicolumn{2}{|c|}{ Multivariable } \\
\hline Variables & HR $(95 \%$ CI $)$ & $P$ value & HR $(95 \%$ CI $)$ & $P$ value \\
\hline Age $>75$ y & $1.47(0.85-2.09)$ & .346 & & \\
\hline Ejection fraction $<45 \%$ & $1.69(1.12-2.26)$ & .035 & $1.89(1.18-3.02)$ & .013 \\
\hline Female gender & $1.34(0.54-1.86)$ & .823 & & \\
\hline Chronic renal failure & $1.01(0.78-1.12)$ & .085 & $1.02(1.01-1.04)$ & .006 \\
\hline Peripheral artery disease & $1.12(0.98-1.12)$ & .215 & & \\
\hline Diabetes & $1.34(0.03-1.70)$ & .782 & & \\
\hline Chronic obstructive pulmonary disease & $1.53(0.91-1.21)$ & .576 & & \\
\hline Multivessel disease & $1.79(1.1-2.7)$ & .045 & $1.81(1.32-2.65)$ & $<.001$ \\
\hline STEMI/nSTEMI $<90 \mathrm{~d}$ & $1.91(1.10-2.80)$ & .007 & $3.2(1.7-6.9)$ & $<.001$ \\
\hline
\end{tabular}

HR, Hazard ratio; $C I$, confidence interval; STEMI, ST-elevation myocardial infarction; $n S T E M I$, non-ST-elevation myocardial infarction; MACCE, major adverse cardiac and cerebrovascular events.

When compared with isolated coronary artery bypass on the LAD, PCI stenting with DES still has a higher rate of target vessel revascularization ranging from $10.77 \%$ to $33.5 \% .^{15-17}$

MIDCAB, since its introduction in clinical practice in 1996, allows surgeons to achieve the optimal result for LITA-LAD grafting avoiding sternotomy and CPB. Because of a tutorship period in another institute with a surgeon expert in MIDCAB providing all tips and tricks, we did not experience a steep learning curve. Our initial experience of the first consecutive 150 cases has been reported, ${ }^{8}$ but patients have been included in this series. The learning curve did not affect the clinical results, but did affect longer operative times and imperfections in LITA harvesting.

In our series, the mean European System for Cardiac Operative Risk Evaluation II was higher than usual in the population undergoing coronary artery bypass grafting $(\mathrm{CABG})^{18}$ because we treated many high-risk patients excluded from conventional CABG surgery, especially when the functional LAD single-vessel disease population is concerned.
Our perioperative mortality of $0.8 \%$ compares favorably with $2.1 \%$ for off-pump single bypass grafting reported in the literature in a similar population. ${ }^{19}$

Our study compares favorably with a systematic review of MIDCAB short and mid-term results ${ }^{20}$ reporting short-term reintervention on target vessel of $8.9 \%$, conversion rate to sternotomy $/ \mathrm{CPB}$ of $0 \%$ to $6.2 \%$, and perioperative infarction rates of $0 \%$ to $3.9 \%$. Of note, we reported only 1 early reintervention on the target vessel, a $2.1 \%$ conversion rate, and a $1.5 \%$ infarction rate. Our patients did not experience ventricular fibrillation or hemodynamic instability leading to emergency $\mathrm{CPB}$, which is different from other reports of intraoperative accidents. ${ }^{21}$ Although the physiologic effect of ischemic preconditioning has never been confirmed, ${ }^{22}$ we routinely perform and strongly recommend an 8-minute LAD occlusion followed by 1-minute reperfusion before the anastomosis. This strategy could be useful to prevent sudden unexpected life-threatening complications during the completion of anastomosis.

As for sternotomy off-pump coronary surgeries, we prefer to avoid the use of coronary shunts whenever possible because of their possible role in intimal lesions. ${ }^{23}$ For the 


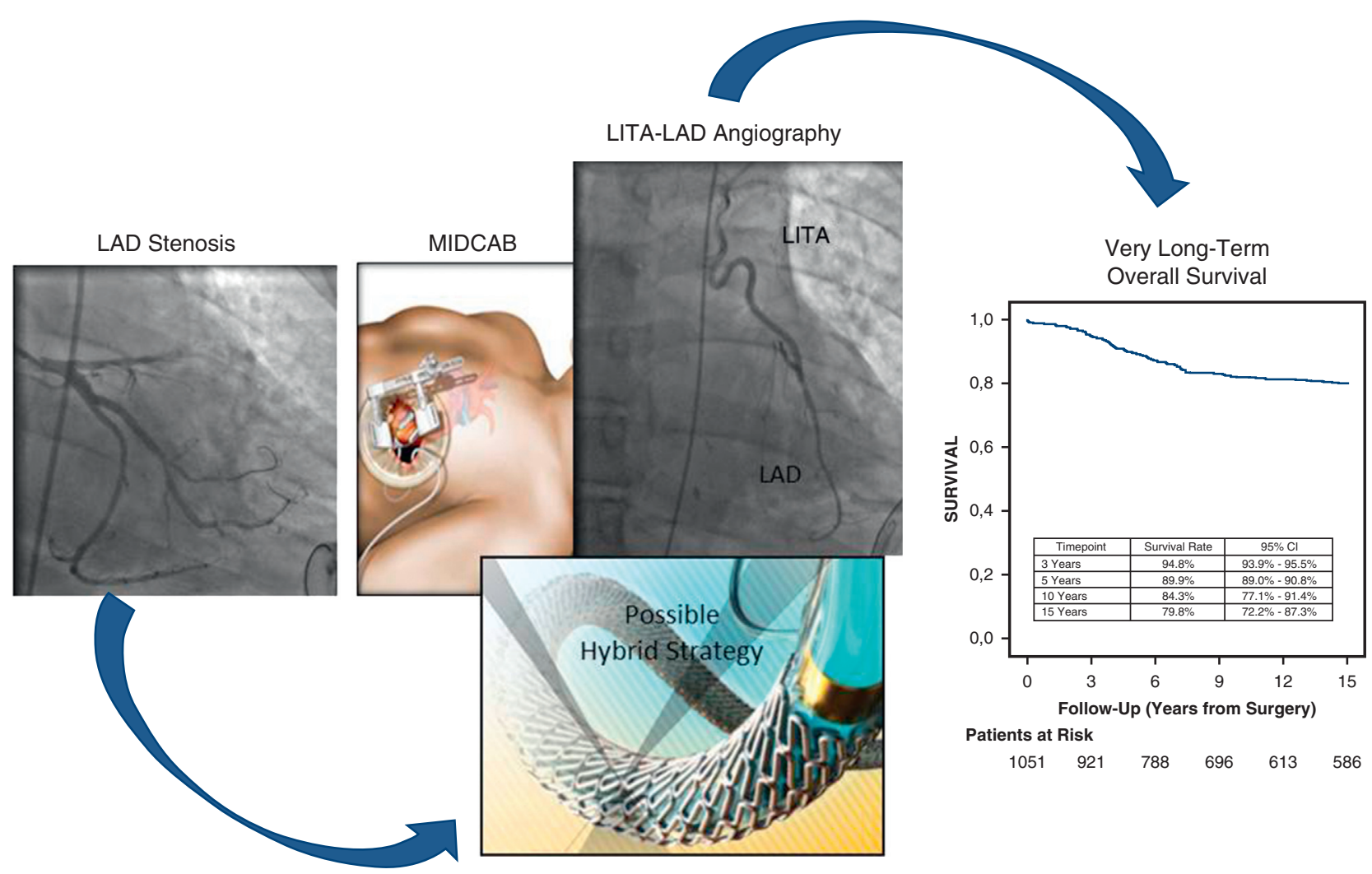

FIGURE 4. Graphical abstract. MIDCAB approach could provide a useful revascularization solution in patients with single-vessel disease and multivessel disease, even in a hybrid revascularization program, achieving good long-term survival results. $L A D$, Left anterior descending; $M I D C A B$, minimally invasive direct coronary artery bypass; LITA, left internal thoracic artery; $C I$, confidence interval.

same reason, we occlude the LAD only proximally and control distal bleeding with a blower. With our preconditioning, the temporary coronary test occlusion has a duration approximately the same as the anastomosis time, and was reliable and safe in predicting a potential hemodynamic instability.

Holzhey and colleagues ${ }^{24}$ found a long-term 10 -year survival of $76.6 \%$, which compares favorably with our study $(84.3 \%)$, as well as freedom from MACCE $(70.9 \%$ vs $82.1 \%$ ). In this study, freedom from angina was not considered an objective event, but included as a composite end point, so it may influence the difference.

Angiography performed in all patients within 10 years of follow-up showed patent LITA-LAD graft in $96.8 \%$ of cases, with 36 diseased grafts. In our series, totally endoscopic coronary artery bypass and robotically assisted coronary artery bypass were excluded, potentially explaining the worse patency rates reported in other studies. ${ }^{21,24}$

MIDCAB is more challenging than conventional CABG and more expensive than stenting. ${ }^{25}$ Nevertheless, a higher rate of repeated proximal LAD stenting at 6 months $(4.8 \%$ vs $0 \%$ ) is reported ${ }^{16}$ when compared with MIDCAB, ${ }^{1-3,26}$ nullifying the initial cost-saving of the interventional procedure.
In a prospective trial comparing PCI with LITA-LAD onpump grafting, ${ }^{27}$ a significantly higher rate of myocardial infarction, additional revascularization, and lower freedom of major events at 5-year follow-up were reported. The results of other more recent 5-year outcomes analysis of stenting versus bypass operation for MVD reported a significantly lower reintervention rate in the bypass group, with no significant difference in mortality and MACCE. ${ }^{28}$ The same results were observed in the single 10-year follow-up randomized trial ${ }^{29}$ that compared MIDCAB and LAD bare-metal stenting; identical results were identified for death and infarction, whereas a higher revascularization rate was recorded in the PCI group (34\% vs $11 \%$ ).

Although those events occurred mainly within the first 7 months, it must be underlined that clinical consequences can be more serious for patients with stent complications compared with patients with graft occlusion. ${ }^{30}$

In addition, the benefits and patency of the LITA-LAD graft exceed a 10-year time period, ${ }^{1}$ and a recent article ${ }^{31}$ suggests that LITA grafting to the LAD is associated with a significantly lower risk of downstream coronary and conduit disease progression compared with PCI.

Therefore, we value MIDCAB to address proximal LAD lesions especially in younger patients and in patients with 
diabetes, because its advantages and patency rates are well established and validated on time. Despite encouraging results, only a few cardiac surgery centers even consider MIDCAB as a first choice for LAD revascularization, advocating many reasons, such as technical difficulty, low incidence of patients with isolated proximal LAD lesions, and lack of cooperation with the referring interventional cardiologists. Nevertheless, cardiac surgery centers that developed a serious MIDCAB program published good results in terms of feasibility, safety, and efficacy, and recent data on long-term follow-up are available..$^{1,21,24,31}$

Our study provides one of the longest follow-ups on a large series of MIDCAB operations. The MIDCAB approach could provide a useful revascularization solution in patients with single-vessel disease and multivessel disease, even in a hybrid revascularization program, achieving good long-term survival (Figure 4).

\section{Study Limitations}

The major limitation is the retrospective design of the study. Moreover, the study describes the results of a single experienced surgeon; therefore, outcomes cannot be generalized without caution. Patient selection, surgical technique, and postoperative care have been well standardized, yielding our series homogeneous.

\section{CONCLUSIONS}

MIDCAB without $C P B$ is safe and effective in routine revascularization of the LAD. The perioperative course is usually uneventful with early recovery and no complications. Our experience provides a positive message in favor of a wider diffusion of this minimally invasive strategy for isolated LAD disease, although more data are required to support our conclusions. Further implications in association with PCI for hybrid revascularization are under investigation, and more studies are required to validate the strategy.

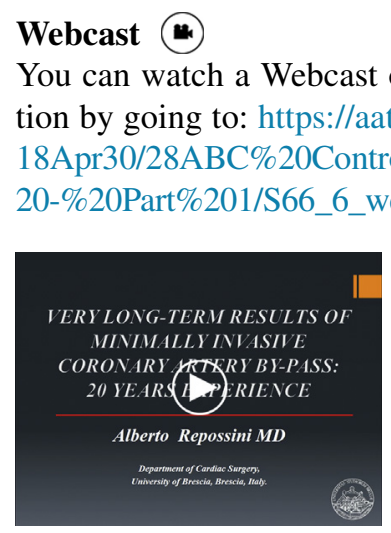

\section{Conflict of Interest Statement}

Authors have nothing to disclose with regard to commercial support.

\section{References}

1. Blazek S, Holzhey D, Jungert C, Borger MA, Fuernau G, Desch S, et al. Comparison of bare-metal stenting with minimally invasive bypass surgery for stenosis of the left anterior descending coronary artery: 10-year follow-up of a randomized trial. JACC Cardiovasc Interv. 2013;6:20-6.

2. Blazek S, Rossbach C, Borger MA, Fuernau G, Desch S, Thiele H, et al. Comparison of sirolimus-eluting stenting with minimally invasive bypass surgery for stenosis of the left anterior descending coronary artery: 7-year follow-up of a randomized trial. JACC Cardiovasc Interv. 2015;8:30-8.

3. Benedetto U, Raja SG, Soliman RF, Albanese A, Jothidasan A, Ilsley CD, et al. Minimally invasive direct coronary artery bypass improves late survival compared with drug-eluting stents in isolated proximal left anterior descending artery disease: a 10-year follow-up, single-center, propensity score analysis. $J$ Thorac Cardiovasc Surg. 2014;148:1316-22.

4. Wijns W, Kolh P, Danchin N, Di Mario C, Falk V, Taggart D, et al. Guidelines on myocardial revascularization; the task force on myocardial revascularization of the European Society of Cardiology (ESC) and the European Association for Cardio-Thoracic Surgery (EACTS). Eur Heart J. 2010;31:2501-55.

5. Reddy RC. Minimally invasive direct coronary artery bypass: technical considerations. Semin Thorac Cardiovasc Surg. 2011;23:216-9.

6. FitzGibbon GM, Burton JR, Leach AJ. Coronary bypass graft fate: angiographic grading of 1400 consecutive grafts early after operation and of 1132 after one year. Circulation. 1978;57:1070-4.

7. Valgimigli M, Bueno H, Byrne RA, Collet JP, Costa F, Jeppsson A, et al. 2017 ESC focused update on dual antiplatelet therapy in coronary artery disease developed in collaboration with EACTS: the task force for dual antiplatelet therapy in coronary artery disease of the European Society of Cardiology (ESC) and of the European Association for Cardio-Thoracic Surgery (EACTS). ESC scientific document group; ESC committee for practice guidelines (CPG); ESC National Cardiac Societies. Eur Heart J. 2018;39:213-60.

8. Repossini A, Moriggia S, Cianci V, Parodi O, Sganzerla P, Baldrighi G, et al. The LAST operation is safe and effective: MIDCABG clinical and angiographic evaluation. Ann Thorac Surg. 2000;70:74-8.

9. Deo SV, Dunlay SM, Park SJ. Dual antiplatelet therapy after coronary artery bypass grafting: does off/on-pump play a role? Am J Cardiol. 2014;113: 1085 .

10. Thygesen K, Alpert JS, White HD, Jaffe AS, Apple FS, Galvani M. Joint ESC/ ACCF/AHA/WHF task force for the redefinition of myocardial infarction, joint ESC/ACCF/AHA/WHF task force for the redefinition of myocardial infarction universal definition of myocardial infarction. Circulation. 2007;116:2634-53.

11. Cutlip DE, Windecker S, Mehran R, Boam A, Cohen DJ, van Es GA, et al; for the Academic Research Consortium. Clinical end points in coronary stent trials: a case for standardized definitions. Circulation. 2007;115:2344-51.

12. Grunkemeier GL, Li HH, Naftel DC, Starr A, Rahimtoola SH. Long-term performance of heart valve prostheses. Curr Probl Cardiol. 2000;25:73-154.

13. Loop FD. Internal-thoracic-artery grafts. Biologically better coronary arteries. $N$ Engl J Med. 1996;334:263-5.

14. Thiele H, Oettel S, Jacobs S, Hambrecht R, Sick P, Gummert JF, et al. Comparison of bare-metal stenting with minimally invasive bypass surgery for stenosis of the left anterior descending coronary artery: a 5-year follow-up. Circulation. 2005; 112:3445-50.

15. Kapoor JR, Gienger AL, Ardehali R, Varghese R, Perez MV, Sundaram V, et al. Isolated disease of the proximal left anterior descending artery comparing the effectiveness of percutaneous coronary interventions and coronary artery bypass surgery. J Am Coll Cardiol Interv. 2008;1:483-91.

16. Roguin A, Camenzind E, Kerner A, Beyar R, Boersma E, Mauri L, et al. Longterm outcomes of stenting the proximal left anterior descending artery in the PROTECT Trial. JACC Cardiovasc Interv. 2017;10:548-56.

17. Hannan EL, Zhong Y, Walford G, Holmes DR Jr, Venditti FJ, Berger PB, et al. Coronary artery bypass graft surgery versus drug-eluting stents for patients with isolated proximal left anterior descending disease. J Am Coll Cardiol. 2014;64:2717-26.

18. Park SJ, Ahn JM, Kim YH, Park DW, Yun SC, Lee JY, et al; BEST Trial Investigators. Trial of everolimus-eluting stents or bypass surgery for coronary disease. N Engl J Med. 2015;372:1204-12. 
19. Kinoshita T, Asai T, Suzuki T, Kambara A, Matsubayashi K. Off-pump bilateral versus single skeletonized internal thoracic artery grafting in high-risk patients. Circulation. 2011;124(11 Suppl):S130-4.

20. Kettering K, Dapunt O, Baer FM. Minimally invasive direct coronary artery bypass grafting: a systematic review. J Cardiovasc Surg. 2004;45:255-64.

21. Holzhey DM, Jacobs S, Mochalski M, Walther T, Thiele H, Mohr FW, et al. Seven-year follow-up after minimally invasive direct coronary artery bypass: experience with more than 1300 patients. Ann Thorac Surg. 2007; 83:108-14

22. Flameng WJ. Role of myocardial protection for coronary artery bypass grafting on the beating heart. Ann Thorac Surg. 1997;63:18-22.

23. Wippermann J, Albes JM, Bruhin R, Hartrumpf M, Vollandt R, Kosmehl H, et al. Chronic ultrastructural effects of temporary intraluminal shunts in a porcine offpump model. Ann Thorac Surg. 2004;78:543.

24. Holzhey DM, Cornely JP, Rastan AJ, Davierwala P, Mohr FW. Review of a 13year single-center experience with minimally invasive direct coronary artery bypass as the primary surgical treatment of coronary artery disease. Heart Surg Forum. 2012;15:E61-8.

25. Magovern JA, Benckart DH, Landreneau RJ, Sakert T, Magovern GJ Jr. Morbidity, cost, and six-month outcome of minimally invasive direct coronary artery bypass grafting. Ann Thorac Surg. 1998;66:1224-9.

26. Ruel M, Shariff MA, Lapierre H, Goyal N, Dennie C, Sadel SM, et al. Results of the minimally invasive coronary artery bypass grafting angiographic patency study. Thorac Cardiovasc Surg. 2014;147:203-8.

27. Serruys PW, Ong AT, van Herwerden LA, Sousa JE, Jatene A, Bonnier JJ, et al. Five-year outcomes after coronary stenting versus bypass surgery for the treatment of multivessel disease: the final analysis of the arterial revascularization therapies study (ARTS) randomized trial. J Am Coll Cardiol. 2005;46:575-81.

28. Diegeler A, Thiele H, Falk V, Hambrecht R, Spyrantis N, Sick P, et al. Comparison of stenting with minimally invasive bypass surgery for stenosis of the left anterior descending coronary artery. $N$ Engl J Med. 2002;347:561-6.

29. Shirai K, Lansky AJ, Mehran R, Dangas GD, Costantini CO, Fahy M, et al. Minimally invasive coronary artery bypass grafting versus stenting for patients with proximal left anterior descending coronary artery disease. Am J Cardiol. 2004; 93:959-62.

30. Leacche M, Umakanthan R, Zhao DX, Byrne JG. Surgical update: hybrid procedures, do they have a role? Circ Cardiovasc Interv. 2010;3:511-8.

31. Zhang M, Guddeti RR, Matsuzawa Y, Sara JD, Kwon TG, Liu Z, et al. Left internal mammary artery versus coronary stents: impact on downstream coronary stenoses and conduit patency. J Am Heart Assoc. 2016;5(9):e003568.

Key Words: coronary artery revascularization, hybrid revascularization, long-term follow-up, MIDCAB

\section{Discussion}

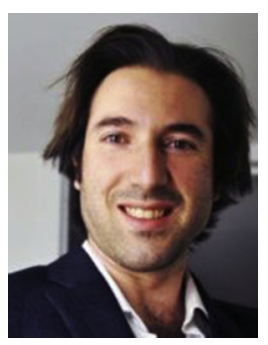

Dr Gianluca Torregrossa (New York, $N Y$ ). It is a pleasure to have the opportunity to discuss this outstanding article representing your own experience with this technique that now you master and are presenting with 20 years' data.

I have a few disclosures before starting my presentation. The first is that I am Italian, as is Dr Repossini, and the second one is that I am highly convinced that MIDCAB is the future of our procedure in coronary artery disease management.

How has your patient population changed throughout these 20 years? You currently work in Brescia, which is less than 1 hour door to door from the hospital of Antonio Columbo.

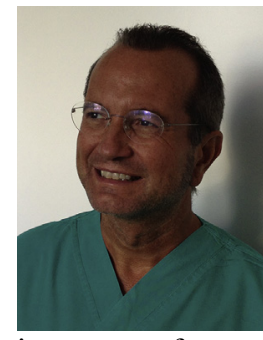

Dr Alberto Repossini (Brescia, Italy). Yes, we live close to a very aggressive interventional cardiologist (Dr Colombo will forgive me), so we are forced to give the patient the maximum minimally invasive procedure possible in competition with PCI stenting. Cardiologists such as Antonio Colombo believe there is no room for cardiac surgery anymore. We just give the patient a message style, save the Ryan soldier, save at least the LAD. So that's the way we started. At the beginning, in 1997 , the LAD was not in the guidelines for PCI, so it was easier to propose a surgical solution to that.

Dr Torregrossa. These are multivessel disease bypass cases treated with a hybrid procedure, or at least in your last year's experience, this is the subset of patients. Now that you have this technique in your hands, how many patients have you seen coming from the catheter lab, a patient with proximal LAD disease, stentable disease in a second vessel, and low SYNTAX score? How many of these patients have been referred to you because of your ability with this technique?

Dr Repossini. All our patients are, let's say, stolen from the catheter lab because they are not surgical patients who have been transformed in hybrid. They are patients who normally should be treated with multiple stents. But whenever the cardiologists realize that you can do a very good job on the LAD in a minimally invasive way with a MIDCAB, they at least call you for implanting the thoracic artery on the LAD and complete the revascularization with stents.

Dr Torregrossa. My second question is about your results. I was impressed by a $98 \%$ follow-up completed, and particularly I would like to mention the more than 600 angiograms or CT scans in patients with 10 years of follow-up. Different than a bypass with a sternotomy and on-pump, the hybrid approach forces and exposes the surgeon to review their own data and detailed angiography. This is something that a sternotomy bypass surgeon a lot of times doesn't have or is not exposed to this. So what did these 600 angiography or CT follow-ups tell you, and specifically those 36 thoracic arteries that had a problem in the follow-up?

Dr Repossini. Yes, you are right, we are probably the most controlled surgeons in the coronary surgery community, because, of course, any thoracic artery that you implant is sooner or later controlled by an angiogram, versus a complete surgical revascularization, which is done once forever and nobody checks anything. When you do a combined procedure, of course you control the thoracic artery. The majority of LITA stenoses were probably due to an harvesting problem at the beginning of the experience in which the retractor was not deep enough to 
harvest all the thoracic artery to its origin. We didn't face any anastomotic problem, because from the LAD we always see the contrast medium going up with a good anastomosis. We faced a lot of problems because of subcritical stenosis of the LAD, and sometimes during the angiographic control, we found an occluded LITA and no stenotic LAD. So probably before the fractional flow reserve, many LAD stenoses have been overestimated.

Readers who found these articles interesting may also like to read the following papers found in recent and future issues of our sister publications, Seminars in Thoracic and Cardiovascular Surgery and Operative

$$
\text { Techniques in Thoracic and Cardiovascular Surgery! }
$$

\section{Adult: Coronary}

CURRENT READINGS: Current Readings: Single vs Bilateral Internal Mammary Artery in Coronary Artery Bypass Grafting. Sary F. Aranki. Semin Thoracic Surg 2018: 398-405.

ORIGINAL SUBMISSION: Functional Evaluation of the Myocardial Ischemia After Coronary Artery Bypass Surgery Using Coronary Flow Velocity Reserve in Left Ventricular Hypertrophy. Kentaro Honda. Semin Thoracic Surg 2018: In press

Commentary: Big Hearts, Little Reserve: Coronary Flow Velocity Reserve After Bypass Grafting in Patients With Left Ventricular Hypertrophy. Juan A. Crestanello. Semin Thoracic Surg 2019: In press

ORIGINAL SUBMISSION: Functional Evaluation of the Myocardial Ischemia After Coronary Artery Bypass Surgery Using Coronary Flow Velocity Reserve in Left Ventricular Hypertrophy. Kentaro Honda. Semin Thoracic Surg 2018: In press

ORIGINAL SUBMISSION: The Prevalence and Distribution of Occlusive Lesions of the Cerebral Arteries in Patients Undergoing Coronary Artery Bypass Graft Surgery: Tomohiro Tsunekawa. Semin Thoracic Surg 2018: 413-420

ORIGINAL SUBMISSION: 'Frozen Apex’ Repair of a Dilated Cardiomyopathy. Masashi Komeda. Semin Thoracic Surg 2018: 406411

Commentary: The Frozen Apex: AUseful Addition to the Surgeons Armamentarium? James Kirklin. Semin Thoracic Surg 2018: 412 


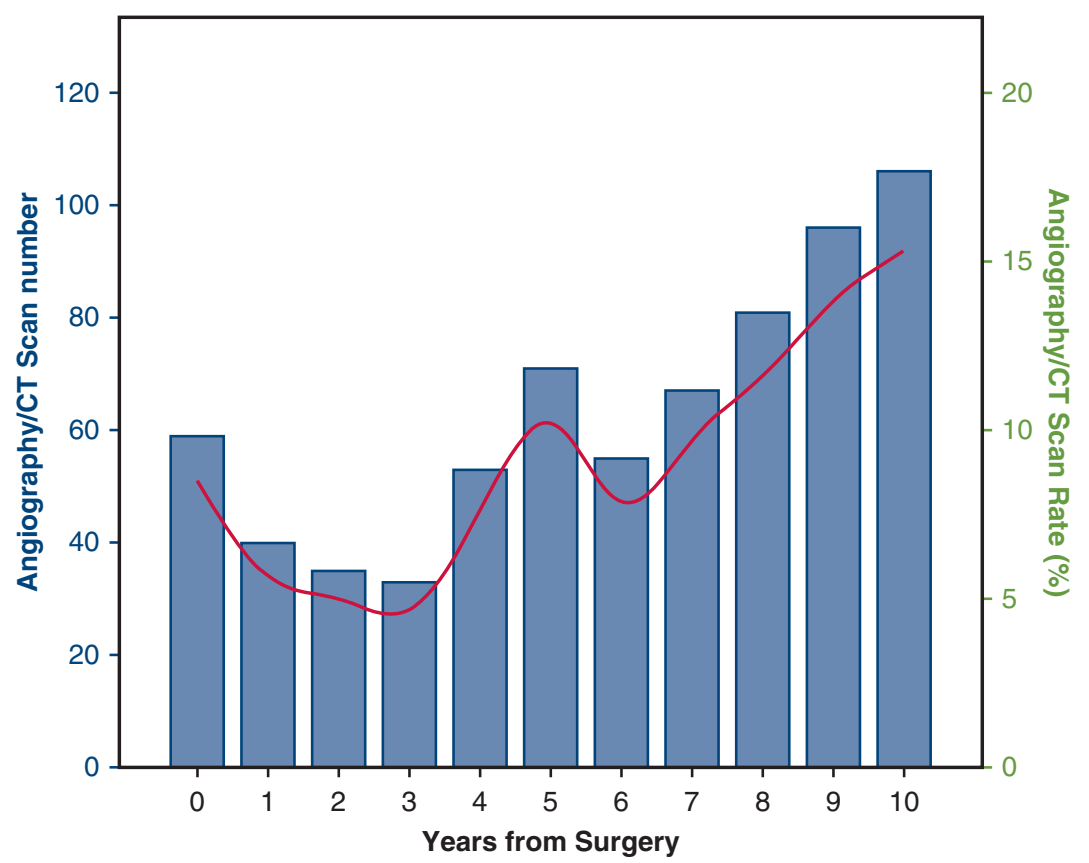

FIGURE E1. Time-related distribution of follow-up angiographies/CT scans. $C T$, Computed tomography.

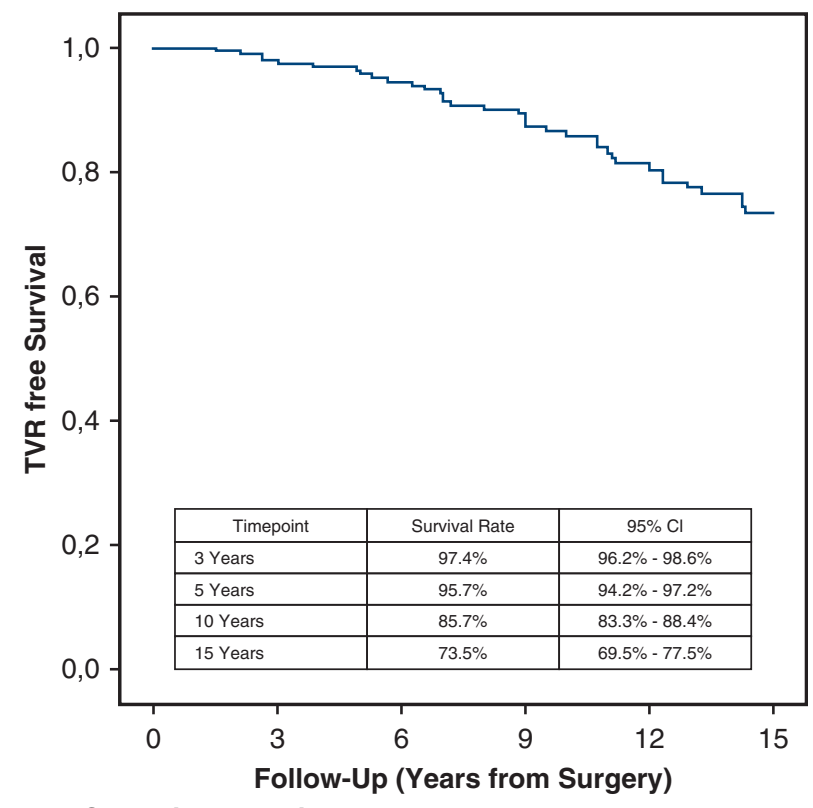

HCR Patients at Risk

$\begin{array}{llllll}195 & 181 & 161 & 125 & 83 & 71\end{array}$

FIGURE E2. Survival freedom from target vessel revascularizations on non-LAD vessel in hybrid coronary revascularization cases. TVR, Target vessel revascularization; $C I$, confidence interval; $H C R$, hybrid coronary revascularization. 